\title{
On "4321" Strategy of English Continuation Writing for Senior High School Students
}

\author{
Jian $\mathrm{Li}^{1}$ \\ ${ }^{1}$ Foreign Language School, Yancheng Teachers University, China \\ Correspondence: Jian Li, Foreign Language School, Yancheng Teachers University, China. E-mail: \\ lijianyc@126.com
}

Received: July 23, 2021

Accepted: September 2, 2021

Online Published: September 19, 2021

doi:10.5539/ells.v11n4p22

URL: https://doi.org/10.5539/ells.v11n4p22

\begin{abstract}
Under the new form of education, the continuation writing task is officially incorporated into college entrance examination English. This is a collision of imitation and innovation, and it is a very good direction of education and teaching. But at the same time, it brings challenges to both English teachers and students who have been stuck in the rigid writing mode. Therefore, they should change writing patterns, select high-quality composition materials reasonably, and set up interesting plots. Then, teachers should organize valid information to improve the students' self-improvement levels. Finally, they should integrate high-quality articles to stimulate writing interest and enthusiasm, thus promoting students' continuation wring abilities.
\end{abstract}

Keywords: "4321" teaching strategy, the English continuation writing, senior high school students

\section{Introduction}

The new question type of continuation after reading fully integrates reading in comprehension skills and writing in expression skills stipulated in the curriculum standard. So, the demand for high school students' English ability has increased a lot, which is hard for students to accept at the moment (Lin, 2015, p. 8). Therefore, this new type of questions has gradually become their weakness. For high school English teaching workers, the traditional English composition guidance method is not suitable for the writing requirement of continuous writing. It is a new challenge to the teachers' teaching of English, and teachers in the teaching process is very difficult to find a new breakthrough. So, it is a challenge for teachers to ask the students to continue writing the composition from the given part of the article.

\section{Previous Studies}

Wang Chuming first proposed the method of "the Continuation Writing" in 2012, based on the two studies of "writing length method" and "interaction and cooperation and foreign language teaching". He outlined two empirical studies to prove his findings. The purpose of the first study is to explore whether there is synergy in post reading continuation and how the synergy plays a role in post reading continuation (Wang, 2017). The experimental results show that the synergy with English input has a significant impact on English learning and output. The purpose of the second study is to discuss the effect of reading materials' interest on post reading continuation. The experimental results show that the interest of the continuation materials does have an impact on the continuation, and the interesting continuation materials can attract students to continue writing, so as to produce better collaborative effect and improve the accuracy of English output.

Lin (2015) explored the influence of post reading continuation on the development of accuracy, complexity and fluency in English writing. Based on the existing problems of previous studies, this study makes improvements: first, previous studies only focus on the immediate response of learners to writing, and do not follow learners' language development for a long time to confirm the learning promotion effect of reading and writing. Second, previous studies have focused only on the influence of post reading continuation on language accuracy, but not on complexity and fluency. Accuracy, complexity and fluency are three interdependent and intersecting aspects in the dynamic system of language use.

Different from previous studies on the effect of sequel after reading on writing, Lin (2015) extended the effect of sequel after reading to the learning of second language vocabulary. The acquisition of target words in the process of continuous writing after reading was tested by thinking aloud data recording. Based on the test results of word 
meaning, word form and usage, the study shows that continuation after reading can promote L2 vocabulary learning, especially in word meaning and usage.

\section{Methodology}

\subsection{Research Purposes}

English teaching is playing an increasingly important role in Chinese education, especially in the college entrance examination. The main purpose of high school English is to cultivate students' ability of listening, speaking, reading and writing. Therefore, writing has become an important part of English teaching. This new type also poses new challenges for English teachers in teaching. I want to analyze and study the teaching and learning of "reading and writing".

\subsection{Research Subjects}

The subjects of the research were made up of a class of Grade One Class 5 Jiangduo Senior High School, in which there are 48 students, 27 are boys and others are girls. Those students had already known continuation task and taught how to complete the task for a month. They knew about the writing rules of continuation task.

\subsection{Research Questions}

The main purpose of this paper is to explore the teaching strategies of the English Continuation Writing Task in senior high school. With the aim of achieving the goal, the writer attempts to answer following questions:

(1) How is effective teaching to be carried out in English writing after reading?

(2) How is the design concept reflected in the specific case analysis?

\subsection{Research Instruments}

On the basis of literature research, this paper adopts the method of action research. Because English writing teaching is a practical task, we need to adjust the teaching mode to achieve the best teaching mode.

Two research instruments were used to collect data for the research: interview and writing test.

\subsubsection{Interview}

Before and after the English writing course, 10 students were selected from the class for face-to-face interviews. From the interview, we can get some feedback from the students. Feedback will provide some suggestions on how to carry out teaching next.

Interview questions:

(1) What's your understanding of the English writing after reading?

(2) Do you think the appearance of continuation after reading has brought great pressure to your English learning?

(3) In the process of writing, what problems and difficulties have you encountered?

(4) What do you think you have improved through specific writing teaching?

\subsubsection{Writing Test}

The English writing test is divided into three parts: the Pre-test, mid-test and post-test. The tests before, during and after the experiment were conducted respectively before, during and after the study. The students' writing works were analyzed to see if their grammar knowledge had improved. Discourse competence and strategy competence are the process of action research (Yang, 2020, pp. 20-30). In order to ensure the repeatability and effectiveness of the test materials, as well as the objectivity and authenticity of the research, the test papers we used are all from English tests from Jiangsu.

\subsection{Data Collections}

This data collection is based on the data analysis of the writing process in three English tests. The students' writing scores are analyzed in three periods: before the experiment, during the experiment and after the experiment. The author will show the change of students' writing ability in the form of table. 
Table 1. Analysis of the writing test results before the experiment

\begin{tabular}{llllllll}
\hline Type & No. & Score & percentage & \multicolumn{2}{l}{ Grade } & \multicolumn{2}{c}{ Class 5, Senior High 1 } \\
\cline { 5 - 7 } & & & & average & percentage & average & percentage \\
\hline Subjunctive & $56-67$ & 55 & 36.67 & 29.11 & 52.92 & 28.96 & 52.65 \\
Objective & $1-55$ & 95 & 63.33 & 62.31 & 65.58 & 60.36 & 63.53 \\
Multiple Choice & $1-55$ & 95 & 63.33 & 62.31 & 65.58 & 60.36 & 63.53 \\
Writing & 66,67 & 55 & 36.67 & 29.11 & 52.92 & 28.96 & 52.65 \\
\hline
\end{tabular}

As shown in the table above, the data analysis of writing test scores before the experiment can be seen. The test should be conducted by 48 people, and the actual test should be conducted by 48 people. The score of this composition is 55 , and the score of the class is 28.96 , which is lower than the average score of the grade. The students' writing situation is not ideal.

Table 2. Analysis of the writing test results in the middle of experiment

\begin{tabular}{llllllll}
\hline \multicolumn{2}{l}{ Score Analysis of 3 Cities in the Mid-term Exam of the $2^{\text {nd }}$} & semester, 2020-2021 & & \\
\hline Type & No. & Score & percentage & Grade & & \multicolumn{2}{c}{ Class 5, Senior High 1 } \\
\cline { 5 - 8 } & & & & average & percentage & average & percentage \\
\hline subjunctive & $56-67$ & 55 & 36.67 & 33.54 & 60.99 & 32.94 & 59.9 \\
Objective & $1-55$ & 95 & 63.33 & 69.32 & 72.97 & 69.23 & 72.88 \\
Blank Filling & $56-65$ & 15 & 10 & 10.71 & 71.38 & 10.3 & 68.67 \\
Writing & 66,67 & 40 & 26.67 & 22.84 & 57.09 & 22.64 & 56.61 \\
\hline
\end{tabular}

As shown in the table above, the data analysis of writing test scores in the middle of experiment can be seen. The test should be conducted by 48 people, and the actual test should be conducted by 48 people. The score of this composition is 40 , and the score of the class is 22.64 , which is a little lower than the average score of the grade. Students' writing has been improved.

Table 3. Analysis of the writing test results after the experiment

\begin{tabular}{llllllll}
\hline \multicolumn{2}{l}{ Score Analysis of $3^{\text {rd }}$ Monthly Exam of the $2^{\text {nd }}$ semester, $2020-2021$} \\
Type & No. & Score & percentage & Grade & & \multicolumn{2}{l}{ Class 5, Senior High 1 } \\
\cline { 5 - 8 } & & & & average & percentage & average & percentage \\
\hline subjunctive & $56-77$ & 55 & 36.67 & 29.62 & 53.85 & 30.02 & 54.58 \\
Objective & $1-55$ & 95 & 63.33 & 62.3 & 65.58 & 60.59 & 63.77 \\
Blank Filling & $56-75$ & 20 & 13.33 & 8.33 & 41.63 & 7.85 & 39.26 \\
Writing & $76-77$ & 35 & 23.33 & 21.29 & 60.83 & 22.17 & 63.34 \\
\hline
\end{tabular}

As shown in the table above, we can see the data analysis of writing test scores after experiment. The test should be conducted by 48 people, and the actual test should be conducted by 48 people. The score of this composition is 35 , and the score of the class is 22.17 , which is higher than the average score of the grade. Students' writing ability has been greatly improved. The teaching effect is obvious and effective.

\section{Results and Discussion}

\subsection{Results}

\subsubsection{Teaching Design of “4321” Strategy}

Teachers are designers. One of the most basic jobs of this profession is to design reasonable and scientific curriculum plan and learning experience activities to meet the specific growth needs of students. Teachers are also evaluation designers. They can guide their own teaching work by diagnosing students' current learning situation and learning needs, so that teachers, students and students' parents can check whether the teaching work achieves the expected effect.

There are two misunderstandings in the traditional teaching design, which are obvious in the whole process of education from kindergarten to university. The first type is "only do it without moving your mind". Students think their task is only participation, and that learning is only activity. They do not deeply think about the meaning of activities, neglect the subjectivity of their own learning. The second type is "instillation learning" 
and students try their best to learn all materials within the specified time according to the teaching materials and teachers' instruction. Instilling is a derogatory word, because when instilling content, students will be submerged in endless facts, opinions, and reading, and rarely feel the essence of learning.

How can we make more students understand what they want to learn through reasonable and scientific teaching design? As a matter of fact, most of the students who say "I understand" may understand the knowledge only by luck, so how to make our teaching plan can make every student be affected by the knowledge, including those who are lack of experience, those who have higher ability and lack of learning motivation, those who are slightly less capable, and those who have different personalities and interests (Zamel, 1983, pp. 165-168)

\subsubsection{Effectiveness of “4321" Strategy}

Firstly, we should cultivate students' creative ability from reading. Teachers should attach importance to the cultivation of students' thinking ability. Teachers can use examples in life to guide students' thinking. This guidance will not only play a better effect, but also for the cultivation and development of students' innovative thinking is very effective. This kind of flexible teaching thinking may make students more comprehensive when they think about problems, which makes the classroom of reading teaching more vitality and creativity (Zhang, 2021, p. 277). Ask students to think actively and have a heated discussion with their peers. This will help students develop critical thinking skills.

Secondly, teachers should guide students to analyze the structure of articles scientifically, grasp the core points and develop students' logical thinking ability. Generally speaking, there is a certain internal logical relationship in the articles of "continuation after reading". In writing, the most important is the six elements of writing: time, place, characters and the cause, process and result of events. In practical training, students often ignore the role of the six elements. Teachers need to make students clear the context of the article according to the six elements, find out the key words and clues, and grasp the core points.

Thirdly, teachers should select the quality of the articles and set the corresponding plot. Generally speaking, narrative is a more appropriate style, which can be used as "writing after reading" exercise materials. Most of the story plots, students can create more space.

Finally, teachers guide students how to integrate high-quality articles. The integration of high-quality articles is the key for students to get high marks. Senior high school English teachers can use the power of big data to effectively integrate high-scoring compositions, together with artificial supplementary explanations. They can create a standard and practical corpus "Warehouse" for the overall English cognitive level of senior high school students and help them to have "Words" to say as they read and write (Liu \& Clare, 2014, p. 96).

a. Main idea: The protagonist Aram is eager to be a baker in the future. During the summer vacation, he wants to go to Mrs Rossi's bakery to learn how to bake, but Mrs Rossi is too old to bake any more, so he just asks Aram to be a cashier. Mrs Rossi was inspired by the memories of making bread and cake. At this time, Aram came up with an idea that he could ask Mrs Rossi to teach him how to bake. How will the story develop?

b. Text features: This story takes the conflict that the protagonist wants to learn baking, but Mrs Rossi is old and has given up baking as a clue, and asks the students to continue to write the following story. The whole story is easy to understand and the conflict is obvious. From the title of the article Aram and Rossi's bakery, the final result may be that Mrs Rossi teaches Aram to do baking and opens a bakery together.

c. Design concept: This lesson attempts to use " 4321 " method to guide students how to analyze the continuation of the article, find out the plot, emotional change, conflict and theme from the reading article. And then analyze the two opening sentences according to the three principles, so that students can understand the plot design problems in writing. Then we give a simple language instruction, and let students learn how to use descriptive language to upgrade their writing through examples. Finally, guide the students to write a good ending (Edge, 1980, pp. 146-148). 


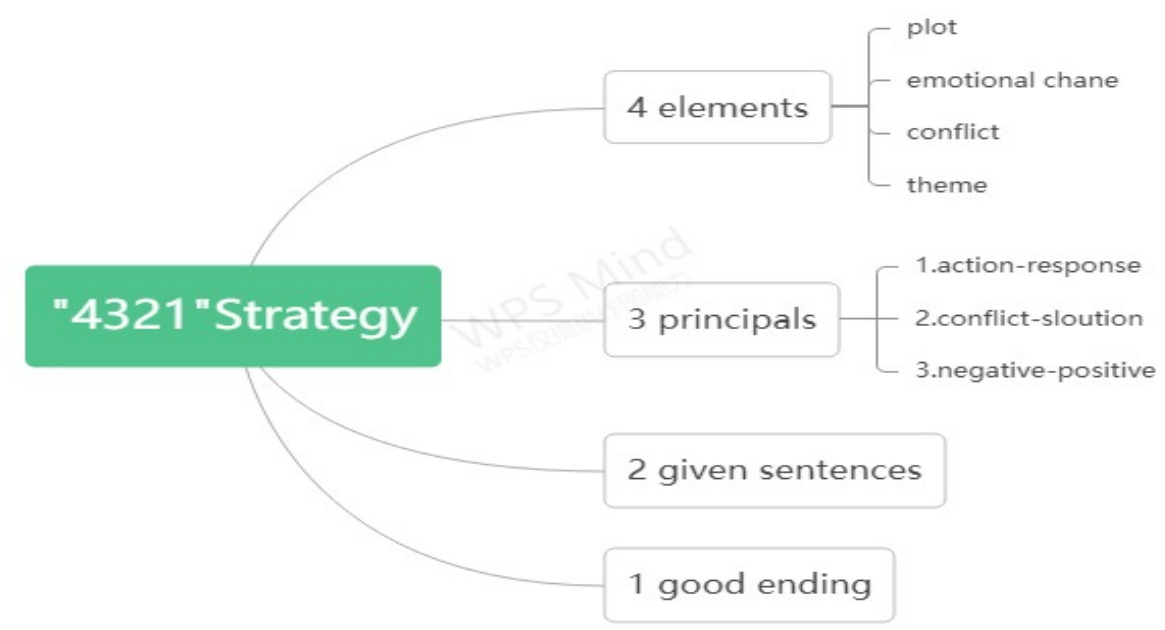

Figure 1. Framework " 4321 ” strategy of continuation writing

\subsection{Discussion}

\subsubsection{Reasons for the Implementation of Teaching Strategies}

The current situation of English writing teaching is that most teachers only ask students to recite English composition templates before the test and apply them in the test. After the examination, the teacher will not evaluate the students' compositions because of the limited time, and there is a lack of continuous and effective communication between teachers and students, which leads to the neglect of English writing. Over time, students will lose interest and enthusiasm in English composition. As a result, students' grades have dropped a lot. Parents and teachers are both worried about it.

Next, teachers do not recognize the role of English reading and writing exercises in senior high schools, and teachers lack relevant teaching experience in reading and writing. The original teaching mode of writing can not meet the needs of students and the teaching effect is poor, which poses a greater challenge to the teaching level of teachers. Therefore, effective teaching of English continuation after reading is particularly important in today's English education (Mohamed \& Rabea, 2020, p. 10).

\subsubsection{Analysis of Students' Specific Cases}

Before the experiment, a writing test was conducted. I randomly selected a student's writing in the class for analysis. The marks are given by many experienced teachers in the school.

This article tells the story of the author who just came to the United States and can't speak English, feeling lonely and afraid. Fortunately, the author learned from various popular cultures and fell in love with English. 


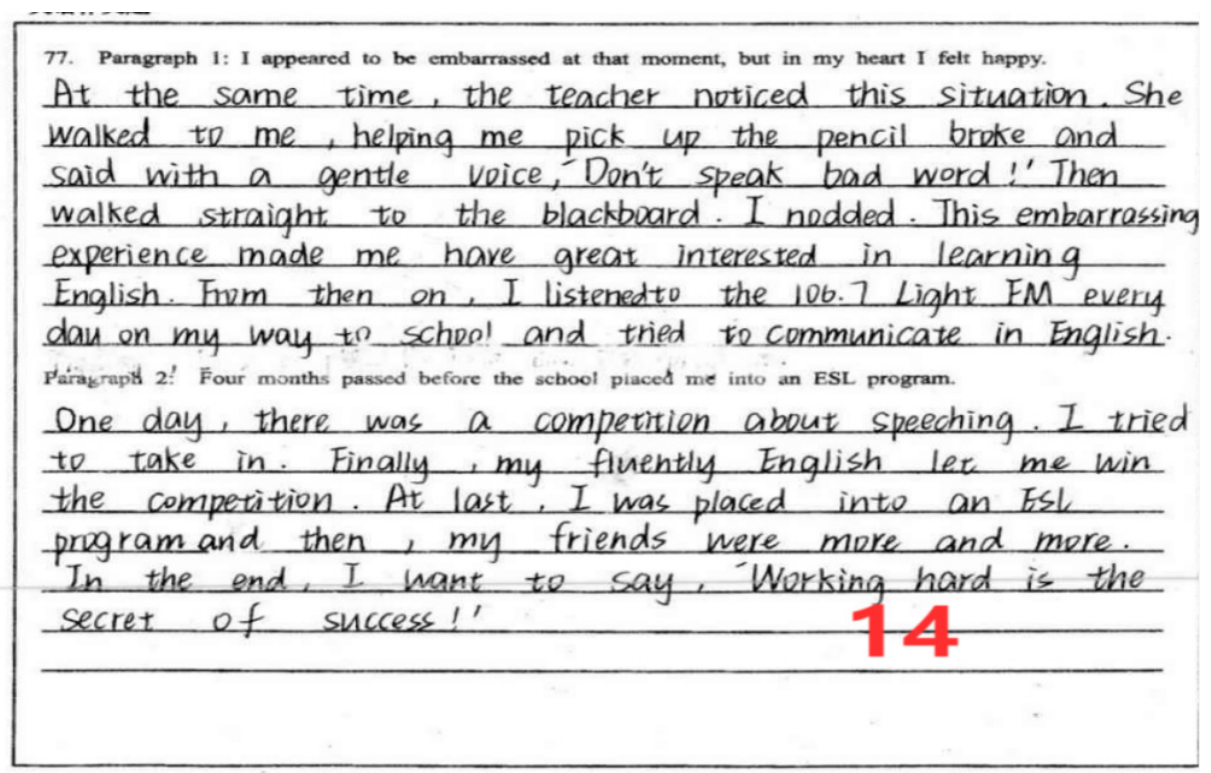

Figure 2. A sample of a student's continuation writing

First of all, given the first paragraph of the continuation, the author felt very embarrassed, but when he spoke English in front of everyone, he was also very happy. Students in this paragraph put the emphasis on the teacher who asked the author not to swear. Obviously, students only understand the sentence from the surface instead of the deeper meanings of the article. The lack of reading ability of this part of students can be seen. After speaking English for the first time, the author became interested in English and listened to the radio daily. This part of the overall direction is correct, the author in the future life, continued to practice English, trying to communicate with students in English, whose English level continues to improve.

At the beginning of the second paragraph, the school asked me to join the ESL project four months later. The student design writer participated in a speech contest and won it. Gradually, the author made many friends. The logic is smooth, but students ignore a very important point that is popular culture. Therefore, when narrating the story, we should finally mention that the author has made such a big change thanks to the popular culture.

As far as this article is concerned, students' reading ability stays on the surface and they can't understand the article creatively. For the analysis of the structure of the article is not clear enough, so did not grasp the core element-popular culture. The final choice of words and sentences is also relatively single, and the final integration of the article is not complete and comprehensive.

After the experiment, the writer took another English test and selected the same students as the last one. The marks are given by many experienced teachers in the school. During the experiment, effective teaching strategies are carried out for students. At the same time, we also had face-to-face communication with students to understand their needs. 


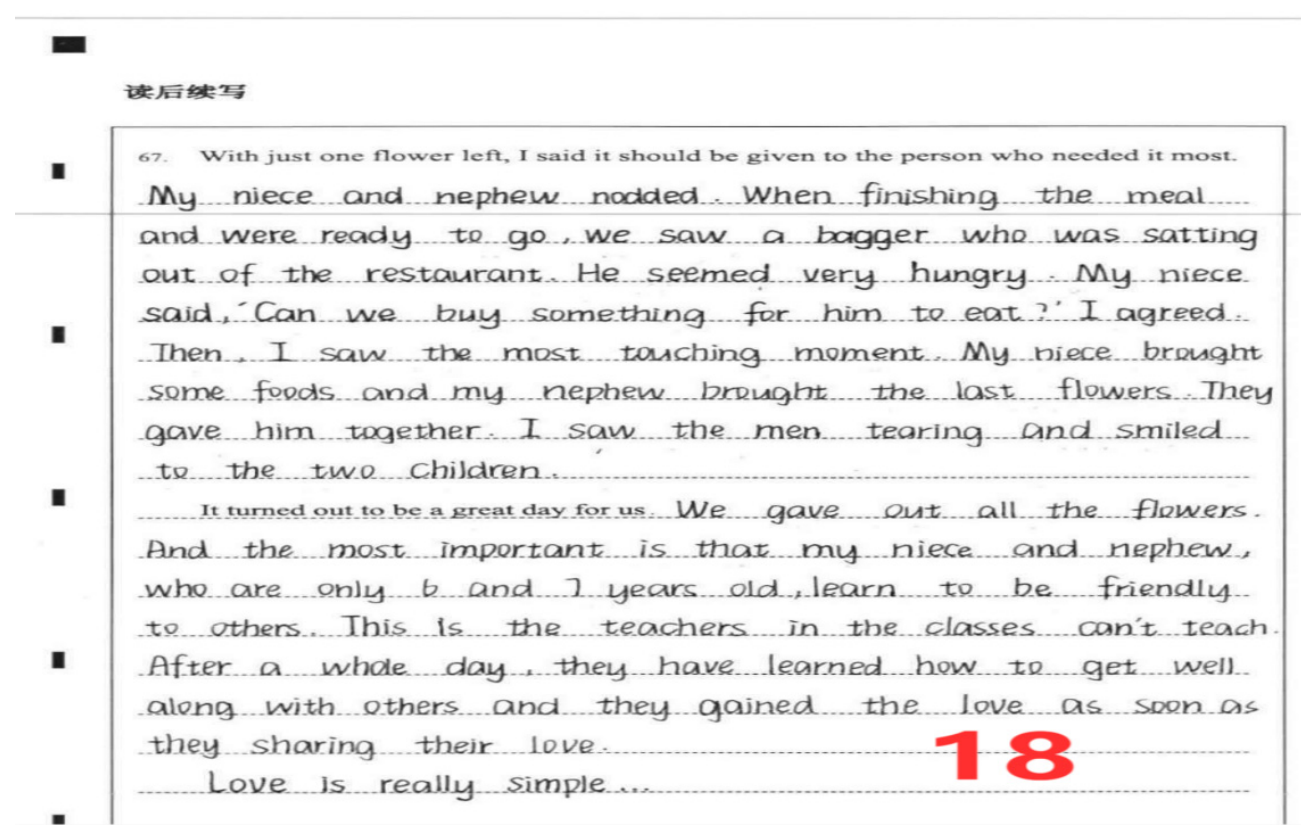

Figure 3. A sample of a student's continuation writing

The author of this article gives 40 flowers he received after graduation to 40 other people. Through sending flowers, we spread a lot of smiles and get many smiles in return.

When there is only one flower left, the author proposes to give it to the people who need it most. Students creatively imagine a beggar character. Children want to buy something to eat for the beggar and want to give him the last flower. At this time, children learn the most precious lesson - to spread kindness to the people around them, they will be very happy. The structure of students' articles is very clear, and grasp the core, so that the logical thinking of the article is smooth.

The second paragraph concludes that today is a good day for them. When they give flowers to strangers, they spread kindness to strangers. Children learn how to love others and get a lot of love from others, which sublimates the theme. The structure and content of the article are very complete, so students get a high score in writing.

The same student's writing scores before and after the experiment have been greatly improved. It can be seen that effective teaching strategies can improve students' writing ability. From this we can see that my argument is of reference value.

\section{Suggestions for the "4321" Teaching Strategy of Continuation Writing}

English writing is an extremely complex social and psychological activity. In order to achieve the leap of students' writing ability, we can only carry out strict training from the foundation. This requires high school English teachers to strengthen the training of students' vocabulary, the use of basic sentence structure and the proper use of tense and voice. Of course, the decisive step is that teachers should provide more space for students to write in English, so that they can use what they learn, abandon the habit of writing at will, find and solve problems in practice (Zhou, 2020, p. 65).

The new curriculum standard points out that in the teaching of English writing in senior high schools in the new century, teachers should no longer be the instigators of "preaching" and "imparting", but the participants in promoting students' learning and the catalyst to mobilize students' enthusiasm.

In writing, we should follow the three principles the author mentioned.

First, students need to grasp the action and psychological reaction of the protagonist in the reading material. Students need to know what the protagonist wants to do and why. This is a superficial understanding of the content of the article. The second and most important point is the conflict point of the article, which is also the creation point for students to write. What does the protagonist want to do, but there is no way to do or achieve, this part of the general article is left for students to write. Therefore, accurately grasping the conflict point of the 
article is the key to students' ability to write articles in line with the theme. The last point is about the overall emotional attitude of the article. The articles given to students are generally positive, sometimes need to sublimate the theme of the article. And students need to learn the correct value orientation.

\section{Acknowledgments}

The paper was funded by "Projects of Jiangsu Higher Education Reforms" (Grant Number: 2019JSJG323).

\section{References}

Edge, J. (1980). Teaching Writing in Large Classes. International Journal of Information and Education Technology, 34(1). https://doi.org/10.1093/elt/34.2.146

Lin, J. (2015). The Effectiveness of the Continuation Task on Second Language Learning of English Articles. English Language Teaching, 8(11). https://doi.org/10.5539/elt.v8n11p79

Liu, X. H., \& Clare, F. (2014). A multidimensional comparison of discourse organization in English and Chinese university students' argumentative writing. International Journal of Applied Linguistics, 24(1). https://doi.org/10.1111/ijal.12013

Mohamed, A. E., \& Rabea, A. (2020, 10). Enhancing Self-Regulated Learning Strategy via Handheld Devices for Improving English Writing Skills and Motivation. International Journal of Information and Education Technology, 10(11). https://doi.org/10.18178/ijiet.2020.10.11.1462

Wang, C. M. (2017). From "Wring Promotes Learning" to "Continuation Promotes Learning". Foreign Language Teaching and Rearch, 49(04).

Yang, L. X. (2020). Effects of Reading Continuation Writing on Senior High School Students' Writing Scores. Master's thesis, Yangzhou University.

Zamel, V. (1983). The composing process of advanced ESL students: six case studies. TESOL Quarterly, 17(2). https://doi.org/10.2307/3586647

Zhang, Q. Y. (2021). Cultivation Strategies of High School Students' Core Competency in English Reading Teaching. Science Consultation, 1.

Zhou, Q. L. (2020). Practical Study of Senior High School English Continuation Writing Pointing to Subject Core Competency. Fujian Elementary Education Study, 1, 65.

\section{Copyrights}

Copyright for this article is retained by the author, with first publication rights granted to the journal.

This is an open-access article distributed under the terms and conditions of the Creative Commons Attribution license (http://creativecommons.org/licenses/by/4.0/). 